\title{
The Exploration and Practice of Transportation Engineering Subject in the Science Popularization Education for Teenagers
}

\author{
Feng Zhou ${ }^{1}$, Ling Hong ${ }^{*}$ \\ ${ }^{1}$ Tongji University, School of Transportation Engineering, Transportation Engineering Shanghai Experimental \\ Teaching Demonstration Center, Shanghai 201804 \\ *Corresponding author. Email: zhoufeng24@tongji.edu.cn, ss980308@tongji.edu.cn
}

\begin{abstract}
The science popularization education of transportation engineering subject is of far-reaching significance for popularizing knowledge, promoting science spirit, and attracting outstanding students to participate in constructing the strong transportation country. This paper takes the construction of the Shanghai Teenager Scientific Innovation Practice Workstation-Tongji University Transportation Engineering Practice Workstation (PW) as an example. It sorts out the difficulties in popularising science for teenagers in universities and explores the hierarchical science popularization education model and operation management mechanism with visiting experience as an entry point, popular science reading materials as auxiliary, popular science courses as the main body, and subject research as orientation. It is hoped to provide a valuable reference for constructing similar science popularization practice bases in universities.
\end{abstract}

Keywords: Teenager, Transportation engineering, Science popularization.

\section{INTRODUCTION}

In 2016, General Secretary Xi pointed out at the "Three Science and Technology Conferences" that scientific and technological innovation and scientific popularization are the two wings of innovation and development, and scientific popularization should be placed as necessary as scientific and technological innovation. In the same year, the Shanghai Municipal Education Commission and the Shanghai Municipal Science and Technology Commission jointly established the "Shanghai Youth Scientific Innovation Practice Workstation" (PW) project. In September 2019, the Central Committee of the Communist Party of China and the State Council issued the "Outline for Building a Powerful Transportation Country." To better implement the strategy of strengthening the country by transportation, the School of Transportation Engineering of Tongji University relied on its first-class subject resources to establish the "Shanghai Youth Scientific Innovation Practice Workstation-Tongji University Transportation Engineering Practice Workstation" in September 2019.
To better integrate and utilize the high-quality resources of universities and research institutes to construct and innovate $\mathrm{PW}$, it is imperative to summarize, reflect, and improve while exploring and constructing[1]. This paper aims to explore PW's science popularization activities, operation management, etc., in the past few years. In addition, to further broaden middle students' scientific horizons, cultivate the innovative spirit, improve practical ability, and accumulate scientific literacy[2], this paper puts forward some suggestions, which can provide reference for the construction of similar science popularization bases.

\section{DIFFICULTIES IN TRANSPORTATION SCIENCE POPULARIZATION AMONG TEENAGERS}

The School of Transportation Engineering of Tongji University, which PW relies on, has a particular reputation worldwide, with rich resources in education, scientific research, and experimentation, and has the resource advantage to carry out transportation science education. However, since PW is in the initial stage of 
exploration, there is no successful experience to follow, and there are also the following difficulties and problems.

\subsection{Huge Subject Knowledge System}

The transportation subject that PW relies on involve professional directions such as traffic, transportation, roads, rails, and information control etc. One of the professional characteristics is the complexity of the system and involves many interdisciplinary subjects. Because the basic education of middle school and the theoretical knowledge of transportation engineering hardly connect with each other, for middle school students, the transportation knowledge is profound and difficult to understand. To achieve easy-to-understand transportation science, it is necessary to mobilize many professional teachers to complete it together.

\subsection{Incomplete Science Popularization Work Mechanism}

Although transportation science popularization has gradually attracted the attention of government, universities, and middle schools, transportation science popularization is relatively lacking in specific policies and measures. Relying on the PW set by the university, science popularization personnel are all part-time by college teachers. Still, whether it is promotion title or job performance evaluation, science popularization work is often not taken into consideration [3]. Science popularization education for teenagers requires teachers to put in lots of energy to condense the esoteric scientific research results into easy-to-understand forms [4]. The science popularisation work mechanism needs to be further improved to attract more excellent teachers to participate in the creation of transportation science popularization [5].

\subsection{Few Forms and Means of Science Popularization}

Owing to the lack of relevant theoretical foundation and professional knowledge of middle school students, it is difficult for some of the college's laboratories and major transportation science experiment equipment to be opened to middle school students, which affects the practical participation of science popularization to a certain extent. The primary forms of domestic transportation science popularization are visit experience and science lectures, which actually cannot meet the needs of teenagers for a systematic understanding and personalized exploration of transportation science [3]. Popular science practice activities need to maintain the advanced nature of technology, means, and concepts to meet the needs of teenagers for knowledge.

\subsection{Lack of an Effective Link between Higher Education and Basic Middle School Education}

At present, the cultivation of scientific and technological practical ability is an essential content of quality education in middle schools, and the development of universities also requires more sources of middle school students with high scientific literacy. As an important bridge connecting higher education and basic secondary education, PW needs to transform highquality transportation education resources into effective support for the cultivation of young people's innovative and practical ability, and at the same time, attract more talents to join the transportation technology team. Finally, a win-win mechanism between colleges and middle schools is formed.

\section{EXPLORATION AND PRACTICE OF TRANSPORTATION SCIENCE POPULARIZATION MODEL}

Establishing effective and diverse science popularization activities is the prerequisite and guarantee for high-quality and effective science popularization. Starting from the specialization of popular science education, PW explored and practised a diversified and hierarchical science popularization model with visiting experience as a cut-in, popular science reading materials as an aid, popular science courses as the main body, and subject research as the orientation.

\subsection{Visiting and Experiencing Activities}

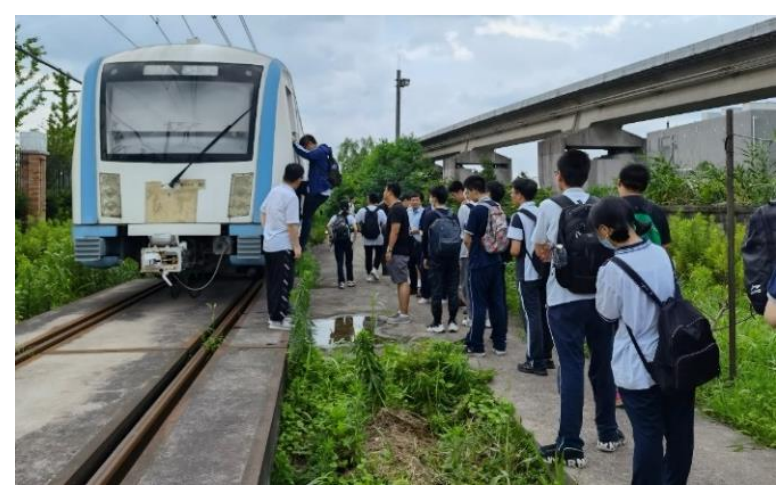

Figure 1 Students visit the teaching and research platform of Tongji University.

Through science popularization days, winter camps, summer camps and other activities, PW invites teenagers to experience the charm of transportation science up close, arranges teenagers to visit related laboratories and participate in interactive experiments (such as rail transit train driving simulation, car driving behaviour simulation, road material recognition, etc.). PW allows teenagers to have zero-distance contact with transportation engineering science and allows students 
to understand the development history, development trends, technical hotspots, academic masters, etc., of the transportation discipline. Through a series of activities, they will stimulate interest and enthusiasm in transportation science and technology, enhance the sense of experience and gain, and arouse ideological resonance.

\subsection{Compile Transportation Science Popularization Books}

Combining the teaching resources of the School of Transportation Engineering, PW organizes teachers to compile a series of science popularization books. The easy-to-understand language and intuitive images are popular among teenagers and people in society. In addition, the primary national transportation engineering research and other related videos are shot with the professional laboratories of the college as the mainline so that teenagers can further understand the charm of transportation science.

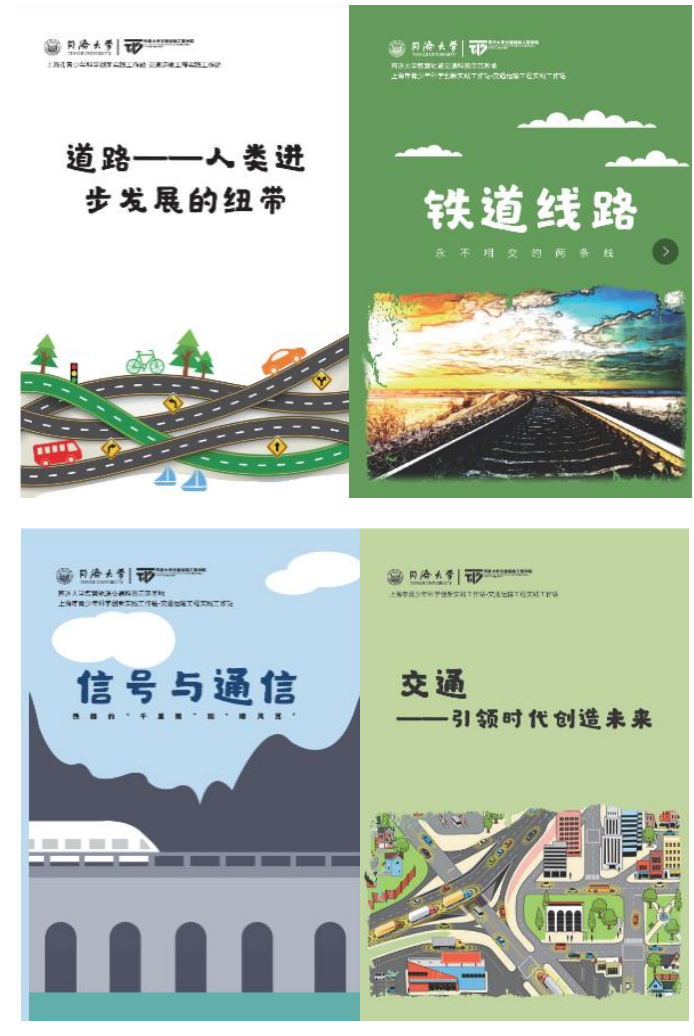

Figure 2 Transportation science popularization books edited by PW.

\subsection{Transportation Series of Science Popularization Courses Enter the Middle School}

In 2020, PW selected "Smart Bus and Shared Transportation", "Smart Rail Transit Line", "Mystery of Metro Network Operation", "Modern Airport System", and other science popularization courses to enter middle school practice sites which teenagers favour. This can guide students to explore intelligent transportation methods and technologies, cultivate students' imagination for future transportation, and promote scientific ideas, cultivate the scientific spirit, and advocate scientific methods. Focusing on the dimensions of history, nature, society, and self, PW will invite professional college teachers to continue designing and launching popular science courses closely related to students' study and life and strengthen the effective connection between higher education in transportation and basic education in middle schools.

\subsection{Middle School Students Come PW to Carry out Transportation Science Research}

PW relies on the research teams of the college to develop and formulate small scientific and innovative research topics, which conform to the cognitive law of middle school students. The research tasks set by the topic ensure that all students can complete on time, get in touch with the frontiers of science and technology, and stimulate their interest in transportation science. PW's tutors provide personalized guidance for each research topic, including experimental design, field investigation, experimental operation, data analysis, and thesis writing. At the same time, PW has set up primary course teaching and training in literature retrieval, research, research methods, experimental skills, and report writing to better master the basic skills of scientific research.

\section{EXPLORATION AND PRACTICE OF OPERATION AND MANAGEMENT OF SCIENCE POPULARIZATION BASE}

The operation and management model of science popularization bases built by universities differs from profitable or non-profit popular science venues in society. As higher education institutions, universities have many outstanding scientific research forces and talents, educational resources, scientific research academic resources, laboratory resources and other advantageous resources, but these resources are all operating in an orderly manner under the existing management model of colleges and universities. To fully ensure the standardized and orderly development of teenager science activities, mobilize teachers' enthusiasm to participate consciously, and make full use of university educational resources and scientific and technological resources, PW has carried out exploration and practice in operation and management.

\subsection{Standardize the Operation}

The construction and popularization of the popular science base is a long-term systematic project with heavy responsibilities and a long way to go. To 
standardize and orderly develop the science popularization base, PW has established a systematic management system. The system clarifies the base's system and management, tasks, organizational structure, and daily management. The management system enables efficient operation of all links, ensuring detailed activity plans and personnel arrangements before each science popularization practice activity and a comprehensive summary after the end of the activity. As a result, PW has been continuously revised and improved during construction and operation.

\subsection{Improve the Mechanism}

The core of continuous innovation in the practical activities of transportation science popularization is to rely on science popularization education talents. The science popularization education work is included in the assessment indicators when promoting titles or assessing job performance to mobilize teachers' enthusiasm for participating in science popularisation activities. Frontline teachers have rich professional knowledge and a broad international vision. They design science popularization courses and research topics for related hotspots in the transportation field so that the theme of science popularization activities is clear and good results have been achieved.

\subsection{Make Full Use of Resources}

University laboratories have abundant science popularization resources and environment atmosphere, which can play an irreplaceable positive role in science popularization. Based on satisfying the experimental teaching of universities, the laboratories of the college's various professional directions are incorporated into the science work system, and the space and time sequence of various teachings are reasonably configured. This plays a vital role in expanding the content of popular science practice activities, improving the utilization rate of resources in university, and optimizing and integrating social resources.

\subsection{Enrich the Course}

The science popularization courses for teenagers should form a system to enable students to establish a complete concept. Relying on the college and teachers, PW has built a popular science curriculum system covering road engineering, traffic engineering, rail transit, transportation organization, traffic and communication control, and traffic safety based on the transportation engineering discipline of the college. The content of the courses in each direction is closely related to cutting-edge research trends, focusing on the integration of new technologies and technologies, and both exciting and exploratory.

\section{CONCLUSION}

Teenagers are the future of the country, and a powerful country in transportation is a national strategy. Therefore, this paper is of great significance for strengthening the science popularization education of transportation for teenagers. After more than three years of exploration, PW's science popularization activity model and content continue to innovate, deepen and expand, and its operation management continues to be summarized and optimized. The students participating in the activity broadened their horizons, improved their scientific literacy, and strengthened their sense of innovation and scientific spirit. The practical results and effects have been highly recognized by students, their parents and schools. The construction of $\mathrm{PW}$ is a systematic and long-term project. Future research can explore constructing a transportation engineering science popularization practice platform with diversified forms, rich content, and sustainable development. In this way, the transportation science popularization will serve the society, the construction of a robust transportation country and an innovative country.

\section{ACKNOWLEDGMENTS}

Shanghai Science and Technology Plan Project (19DZ2330100, Teenager Science and Technology Innovation Education for Future Transportation)

\section{REFERENCES}

[1] Liu Tong, Yang Dingchen. Capacity building and practical results of the science popularization base of Tianjin Normal University under the background of production, education and research[J]. Tianjin Science and Technology, 2021, 48(06): 46-49.

[2] Duan Tao, Chen Ning. Popular Science Education for Adolescents: Concept, Theory and Path[J].Youth Journal,2020(03):66-70.

[3] Liu Xia, Chen Wenhui. Exploration and analysis of youth science education model under the new situation $[\mathrm{J}]$. Science and Technology and Innovation, 2020(12): 76-77.

[4] Jian Zheng. Exploration of innovative paths for youth science education activities [J]. Industry and Technology Forum, 2020, 19(13): 279-280.

[5] LIU Min, YANG Wenxin, LI Weihua, YU Feng, WANG Kaiming, ZHOU Yan. Practice of Science Popularization Education for Youths in Colleges and Universities[J]. Tianjin Science and Technology, 2021, 48(06): 23-24+28. 